\title{
COMPARATIVO DE PERMEABILIDADE ENTRE TINTAS ACRÍLICA E À BASE DE SOLO EM ARGAMASSA DE CAL*
}

\author{
Thainá Silveira Garcia Mendes ${ }^{1}$ \\ Matheus Tolentino Lauar ${ }^{2}$ \\ Beatryz Cardoso Mendes ${ }^{3}$ \\ Márcia Maria Salgado Lopes 4 \\ Marina Keiko Ishihara ${ }^{5}$ \\ Délio Porto Fassoni ${ }^{6}$
}

\section{Resumo}

A manutenção de monumentos e obras históricas deve ser executada com o uso de argamassa de cal, devido à sua maior permeabilidade e por preservar as características originais da obra. Entretanto, o uso de revestimento de tinta acrílica comercial sobre esta argamassa interfere na permeabilidade da construção como um todo, por vedar a superfície das paredes e tetos, internos e externos. Como uma alternativa que permite maior permeabilidade, tem-se a tinta à base de solo, constituída de água, cola branca e solo rico em silte e argila. O presente trabalho tem como objetivo quantificar e comparar as permeabilidades de amostras de argamassa de cal revestidas com tinta acrílica e com tinta de solo. Usou-se o método do tubo de Karsten para medir a permeabilidade dos dois revestimentos em comparação com a argamassa de cal sem revestimento. Os resultados dos ensaios indicaram que o revestimento de tinta à base de solo apresenta permeabilidade significativamente maior que a acrílica, sendo então mais indicada para o uso em restauro e manutenção de edificações históricas.

Palavras-chave: Permeabilidade; Argamassa de cal; Revestimento; Tintas.

\section{COMPARISON OF PERMEABILITY IN LIME MORTARS COATED WITH ACRYLIC PAINT AND SOIL BASED PAINT}

\section{Abstract}

The maintenance repairs of monuments and historical buildings must be executed using lime mortar due to its greater permeability besides to keep the historical aspects of the construction. However, the use of acrylic paint over this mortar influence in the permeability of the whole construction, once it closes the pores of the exterior walls and ceilings. As an alternative, that allows a greater permeability, there is the soil based paint, composed by water, glue, and a soil that contains silt and clay. Therefore, the objective of this study is to measure and compare the permeability of lime mortar samples coated with acrylic paint and soil based paint. The method used to measure the water absorption was the Karsten tube penetration test and the results comparison used samples with no coating as default. As indicated in the results, the soil-based paint allows a greater water absorption when compared to the acrylic paint, and then it is more suitable for historical building repairs and maintenance.

Keywords: Water absorption; lime mortar; Coating; Paint.

1 Graduanda, Departamento de Engenharia Civil, Universidade Federal de Viçosa, Viçosa, Minas Gerais, Brasil.

2 Graduando, Departamento de Engenharia Civil, Universidade Federal de Viçosa, Viçosa, Minas Gerais, Brasil.

3 Engenheira Civil, graduada, mestranda, Departamento de Engenharia Civil, Universidade Federal de Viçosa, Viçosa, Minas Gerais, Brasil.

4 Engenheira Civil, graduada, mestranda, Departamento de Engenharia Civil, Universidade Federal de Viçosa, Viçosa, Minas Gerais, Brasil.

5 Graduanda, Departamento de Engenharia Civil, Universidade Federal de Viçosa, Viçosa, Minas Gerais, Brasil.

6 Engenheiro Civil, mestre, doutorando, Departamento de Engenharia Civil, Universidade Federal de Viçosa, Viçosa, Minas Gerais, Brasil. 


\section{INTRODUÇÃO}

\subsection{CONSIDERAÇÕES GERAIS}

Durante séculos a argamassa de cal era a forma mais utilizada para o assentamento de alvenarias, revestimentos de paredes e regularização de superfícies em uma construção. Contudo, a partir do princípio do século XIX, com o advento do cimento Portland, o uso da argamassa de cal teve seu declínio. No entanto, a argamassa de cal ainda é usada atualmente para a manutenção e restauro de obras históricas. $\mathrm{O}$ uso deste material é justificado por razões estéticas, ao manter o mesmo material usado originalmente, e construtivas, devido às propriedades da argamassa de cal, não presentes na de cimento.

A argamassa de cal é consideravelmente mais permeável do que a argamassa de cimento Portland. Essa propriedade é fundamental para o restauro de obras históricas devido à necessidade de se manter uma passagem de umidade entre o interior e o exterior da construção. Isso se deve ao fato de que estas edificações usam materiais não inertes em sua estrutura, como madeira e barro, e estes realizam trocas de umidade com o ambiente.

Entretanto, após o revestimento em argamassa de cal, as obras históricas ainda recebem mais uma camada em sua superfície: a pintura. Esta camada mais superficial não deve impedir a passagem de umidade, comportando de forma semelhante à argamassa. Um tratamento superficial comumente usados em construções em geral são as pinturas em tinta acrílica, porém sabe-se que estas são bastante impermeáveis, tornando-a incompatível com o uso em restauros.

Devido a esta incompatibilidade, sugere-se o uso de uma tinta alternativa, à base de solo. Esta tinta é de produção artesanal e não utiliza resinas acrílicas, permitindo, teoricamente, uma maior passagem de umidade.

Este estudo tem como objetivo quantificar a passagem de água em amostras de argamassa de cal pintadas com tintas, acrílica e de solo. Com esta análise, será indicada, não o uso de tintas à base de solo para restauro e manutenção de obras históricas.

\subsection{PROPRIEDADES DA ARGAMASSA DE CAL}

A massa de cal, areia e água é uma mistura tradicional na produção de argamassas. A cal, como aglomerante, confere à argamassa boa trabalhabilidade, retenção de água adequada e boa aderência com a alvenaria. Estas propriedades são consequência da finura das partículas de cal, resultando em uma grande superfície específica, o que leva à um maior consumo de água no amassamento. Segundo Santiago [1], uma argamassa pode ser considerada boa a partir da análise de algumas condições, como compacidade, impermeabilidade, aderência e constância de volume.

A trabalhabilidade, de acordo com Bianchin [2], é resultado de outras propriedades, como: consistência, plasticidade, coesão, adesão, dentre outras. Sobre a retenção de água, Cincotto [3] afirma que a esta propriedade é influenciada pelo teor de cal, bem como pela superfície específica dos componentes da argamassa e da relação agregado/aglomerante. 
No entanto, a grande absorção de água devido à cal gera uma grande porosidade na argamassa quando endurecida. Penas [4] aborda que é devido a esta alta porosidade que a argamassa de cal tem grande absorção de água, ou seja, alta permeabilidade.

\subsection{TINTAS ACRÍLICAS}

As tintas mais usadas para a pintura de superfícies em construções são as tintas látex, sendo que estas podem ser acrílicas ou PVA, dependendo da resina utilizada em sua produção. As tintas látex com resina acrílicas são, segundo Cardoso [5], mais duráveis, impermeáveis e possuem maior aderência quando comparadas à tinta látex à base de resina vinílica. Além disso, Castro [6] expõe que o uso de resina acrílica apresenta como vantagens, uma melhor fixação do pigmento, alto brilho, boa adesão e o fato de serem transparentes e não amarelarem com o tempo. Por este motivo, a tinta acrílica é mais recomendada no uso em ambientes externos, devido ao seu maior contato com a umidade e agentes deteriorantes.

Algumas propriedades importantes para o bom desempenho de tratamentos superficiais são a resistência à abrasão, o poder de cobertura e a porosidade. Esta última é especialmente importante por influenciar na permeabilidade da camada superficial, foco do presente estudo.

A composição usual de uma tinta acrílica, de acordo com Faria [7], inclui resinas, solventes, pigmentos (ou carga) e outros aditivos que podem ser usados para o melhoramento da qualidade final do produto.

\subsection{TINTAS DE SOLO}

A tintas à base de solo é resultado da mistura de pigmentos, água e outros aditivos como cola branca ou resina. Os pigmentos utilizados nestas tinas são os minerais de solos siltosos e argilosos. Segundo Cardoso [5], alguns exemplos de minerais usados como pigmentos em tintas são os óxidos, sulfatos, cromatos, carbonatos e fosfatos de metais variados. Em teoria, as tintas à base de solo são mais permeáveis que as látex, por não utilizarem resinas acrílicas ou vinílicas, que vedam os poros da camada superficial.

A coloração destes pigmentos se altera com o tipo de mineral utilizado, sua absorção de luz, tamanho e textura das partículas de pigmento. Dentre os minerais usados na produção das tintas, os óxidos de ferro são usados como pigmentos naturais devido ao seu poder pigmentante e sua gama de cores. No entanto, as impurezas naturais dos solos causam variação nas tonalidades, além disso, quando comparada às acrílicas, as tintas de solo possuem menor durabilidade e menos brilho.

Para a produção de uma tinta de solo com cores mais vivas, Carvalho [8] recomenda o uso de um solo rico em silte e argila como pigmento. Devido à sua simplicidade de composição e produção, a tinta de solo não tem os mesmos padrões de durabilidade e aderência de tintas comerciais, ditas imobiliárias. Porém, Faria [7] cita que as vantagens econômicas, ambientais e sociais do uso da tinta de solo deve ser levado em consideração no momento da escolha do revestimento. 


\subsection{PERMEABILIDADE EM ARGAMASSAS DE CAL}

As argamassas de cal tem como uma de suas propriedades a alta permeabilidade, quando compara às argamassas de cimento. Selmo [9] afirma que a permeabilidade é majorada por alguns fatores, como o aumento no teor de cal, que leva a uma maior absorção de água; elevada relação água/cimento, elevando a porosidade da argamassa quando seca; e alto teor de finos da areia, consumindo mais água no amassamento.

O conhecimento da percolação de água nas argamassas de cal é de suma importância para a boa manutenção das construções. Isso se deve ao fato de que grande parte das patologias encontradas em construções está relacionada à umidade, causando bolhas, mofos e outros danos, estéticos, funcionais e até estruturais.

Além disso, em uso específico para manutenção de obras históricas, a permeabilidade das argamassas deve ser conhecida para assegurar as trocas de umidade dos materiais com o ambiente.

O ensaio do tubo de Karsten é usado para medir o volume de água que penetra nas amostras de argamassa em um determinado tempo. Com os resultados deste ensaio, é possível determinar a permeabilidade de diferentes argamassas, ou, no caso deste trabalho, de diferentes tratamentos superficiais.

\section{MATERIAIS E MÉTODOS}

\subsection{PROCESSO DE PRODUÇÃO DAS AMOSTRAS}

Para a análise da permeabilidade dos diferentes tratamentos superficiais em argamassas de cal, foram moldados 9 corpos de prova em formato cilíndrico de $4 \mathrm{~cm}$ de diâmetro e 1,8 cm de altura com o traço 1:3. A moldagem de cada corpo de prova foi realizada em duas etapas, sendo que em cada uma delas, ocorreu o adensamento da argamassa com o auxílio de um soquete. Os corpos de prova foram submetidos à cura em câmara úmida por 2 semanas, sendo transferidos após esse período para a câmara de carbonatação por um período de 4 semanas. Esse segundo processo, teve como intuito acelerar o processo de carbonatação da argamassa.

Denominou-se P1 (A, B e C) as três amostras de argamassa pintadas com duas demãos de tinta à base de solo; P2 ( $\mathrm{A}, \mathrm{B}$ e $\mathrm{C}$ ), as amostras revestidas com duas demãos de tinta acrílica em sua face superior. Para uma comparação mais detalhada, moldaram-se três amostras sem qualquer tipo de tratamento superficial, estas foram denominadas P3 (A, B e C).

A tinta de solo utilizada neste ensaio foi produzida a partir de um solo amarelo e contém resina no teor de $20 \%$ do peso dos sólidos.

\subsection{ENSAIO DO TUBO DE KARSTEN}

No processo de preparação, os corpos de prova foram vedados com cera em sua lateral e em parte do topo. Em seguida, foram submetidos à saturação até se obter uma constância no peso, colocando a amostra parcialmente submersa em água, de modo que o transporte da água ocorresse apenas pela parte 
inferior da peça. Com as peças saturadas, o Tubo de Karsten foi colocado sobre as mesmas na região do topo onde não havia vedação pela cera. Então, a vedação do tubo com o corpo de prova foi finalizada para que não houvesse vazamento de água, mas apenas o fluxo através do exemplar.

O Tubo de Karsten é um equipamento que tem por objetivo quantificar o volume de água absorvido por uma superfície de área conhecida em um determinado período de tempo. Os resultados obtidos são tratados graficamente, permitindo a obtenção de noções sobre a capacidade de impermeabilização à água da superfície analisada. Deste modo, é possível caracterizar a argamassa quanto à resistência à passagem de água e prever seu grau e sensibilidade de deterioração em serviço. Este ensaio encontra-se caracterizado na ficha do LNEC [10] elaborado com base no teste no.II.4 do RILEM [11]. O tubo, também conhecido como cachimbo, possui uma parte inferior em formato cilíndrico com fundo fechado seguido de um tubo vertical, como é ilustrado nas Figuras 1 e 2. A área superficial de absorção é de $5,067 \mathrm{~cm}^{2}$, e o tubo vertical possui graduação de 1 a $3,5 \mathrm{ml}$, com uma subdivisão de $0,05 \mathrm{ml}$
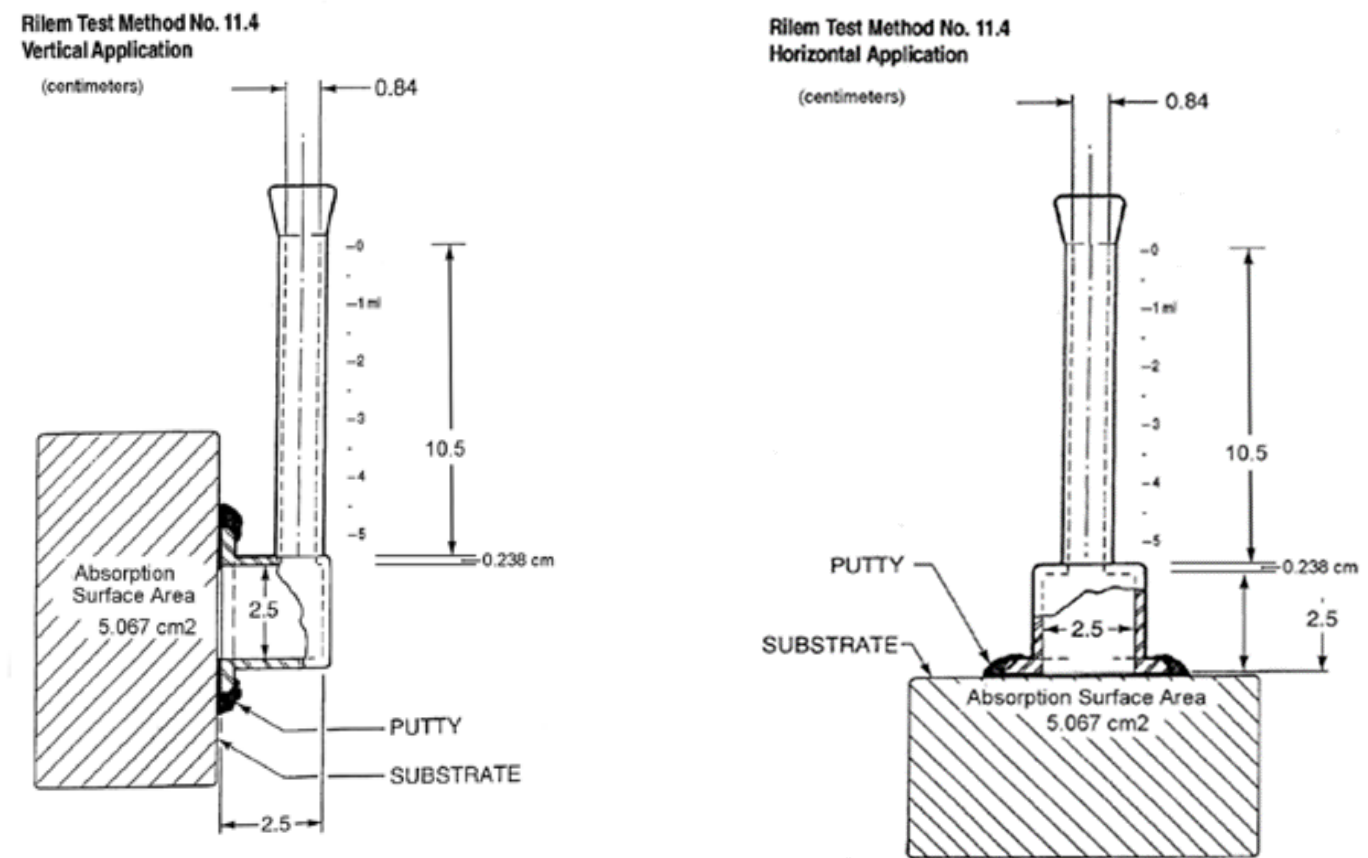

Figuras 1. Tubo de Karsten, também conhecido como cachimbo, posicionado na vertical (Figura 1a) e na horizontal (Figura 1b)

Após a fixação do tubo de Karsten, adicionou-se água até a marcação 0 de sua parte horizontal e inicia-se a contagem do tempo. Durante os intervalos de tempo de 2 minutos, 5 minutos, 10 minutos, 20 minutos, 30 minutos, 40 minutos, 50 minutos e 60 minutos foram coletadas as medidas nas quais o nível da água se encontrava, calculando assim a quantidade de água que atravessou a argamassa.

Os ensaios de permeabilidade através do Tubo de Karsten foram realizados para cada corpo de prova, sendo os resultados expostos na próxima seção. Optou-se nestes ensaios pela substituição do uso de silicone, como sugerido 
pela LNEC [10] para a vedação do tubo e dos exemplares, pelo uso de uma pasta obtida da mistura de cera de abelha com óleo mineral.

\section{RESULTADOS E DISCUSSÃO}

Com os resultados obtidos no ensaio do Tubo de Karsten para os corpos de prova de argamassa de cal revestidos com tinta à base. de solo, denominados de $\mathrm{P} 1$, elaborou-se o gráfico mostrado na Figura 2. O gráfico apresenta 0 volume de água absorvida $\left(\mathrm{m}^{3}\right)$ em relação à raiz quadrada de tempo $\left(\mathrm{t}^{1 / 2} \mathrm{~min}\right)$, que retrata de forma significativa o quão permeável um material pode ser em relação a outros. Observa-se que volume de água absorvida por hora $\left(\mathrm{m}^{3} / \mathrm{h}\right)$ variou entre 1.10 e $1.65 \mathrm{~m}^{3} / \mathrm{h}$.

\section{Argamassas revestidas com Tinta de Solo}

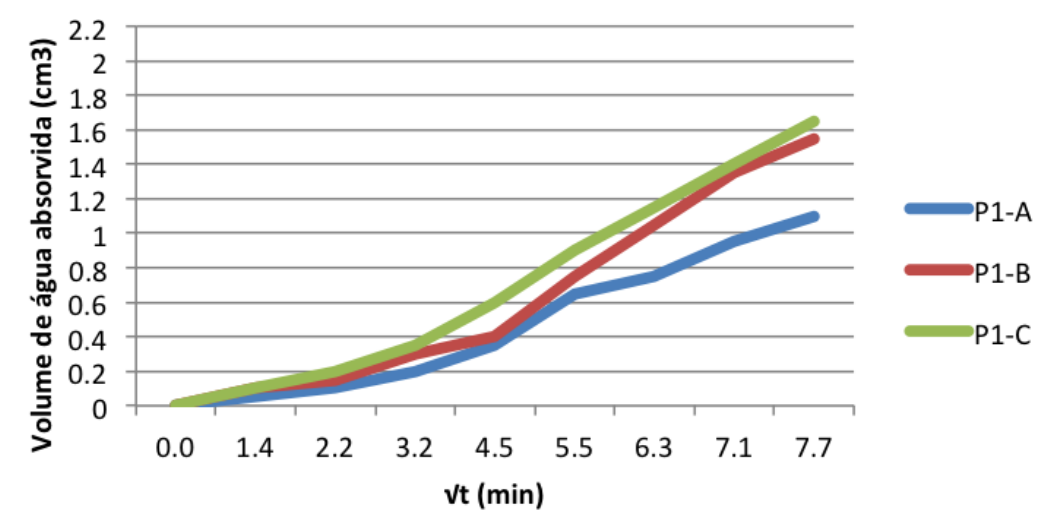

Figura 2. Representação gráfica da evolução da absorção de água por raiz de tempo em argamassas revestidas com Tinta de Solo.

Com relação às amostras $\mathrm{P} 2$, revestidas com tinta acrílica comercial, foram obtidos os valores expressos através do gráfico abaixo (Figura 3). O volume de água absorvida por hora $\left(\mathrm{m}^{3} / \mathrm{h}\right)$, variou entre 0.10 e $0.25 \mathrm{~m} 3 / \mathrm{h}$.

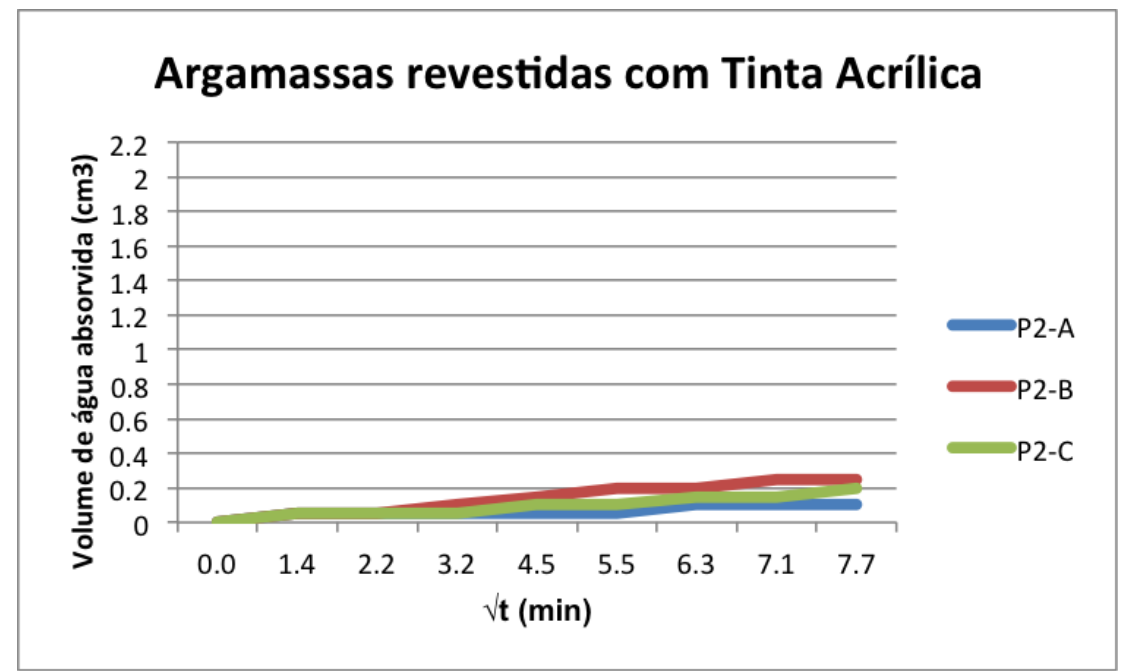

Figura 3. Representação gráfica da evolução da absorção de água por raiz de tempo em argamassas revestidas com Tinta Acrílica 
Para as amostras P3, sem qualquer tipo de tratamento superficial, foram obtidos os valores expressos através do gráfico abaixo (Figura 4). O volume de água absorvida por hora $\left(\mathrm{m}^{3} / \mathrm{h}\right)$, variou entre 1.95 e $2.05 \mathrm{~m}^{3} / \mathrm{h}$.

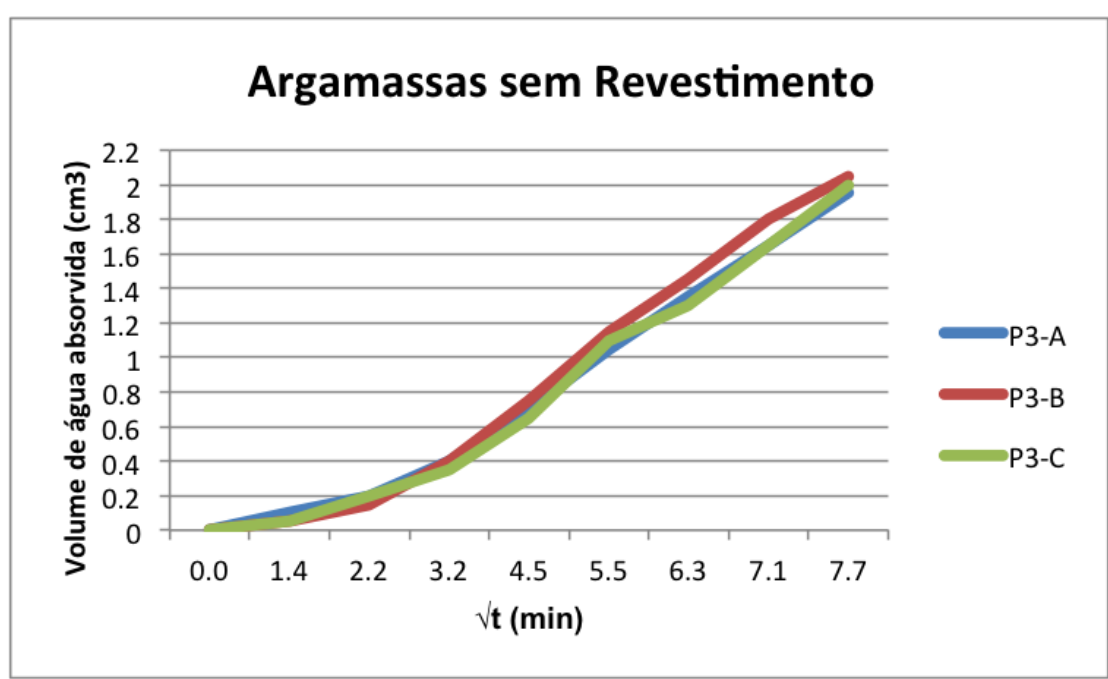

Figura 4. Representação gráfica da evolução da absorção de água por raiz de tempo em argamassas sem revestimento

Pode-se perceber nitidamente, através da análise dos gráficos obtidos para os diferentes tipos de revestimentos, que a argamassa que apresentou um maior índice de absorção de água foi a argamassa não revestida. Em seguida, com valores não muito distantes, tem-se a argamassa revestida com tinta à base de solo. Com resultados muito inferiores em relação aos das demais argamassas, temos os corpos de prova revestidos com a Tinta Acrílica.

Gerou-se um gráfico contendo os volumes de água absorvido ao final de 1 hora de ensaio (Figura 5), com o intuito de facilitar o comparativo entre a permeabilidade das argamassas.

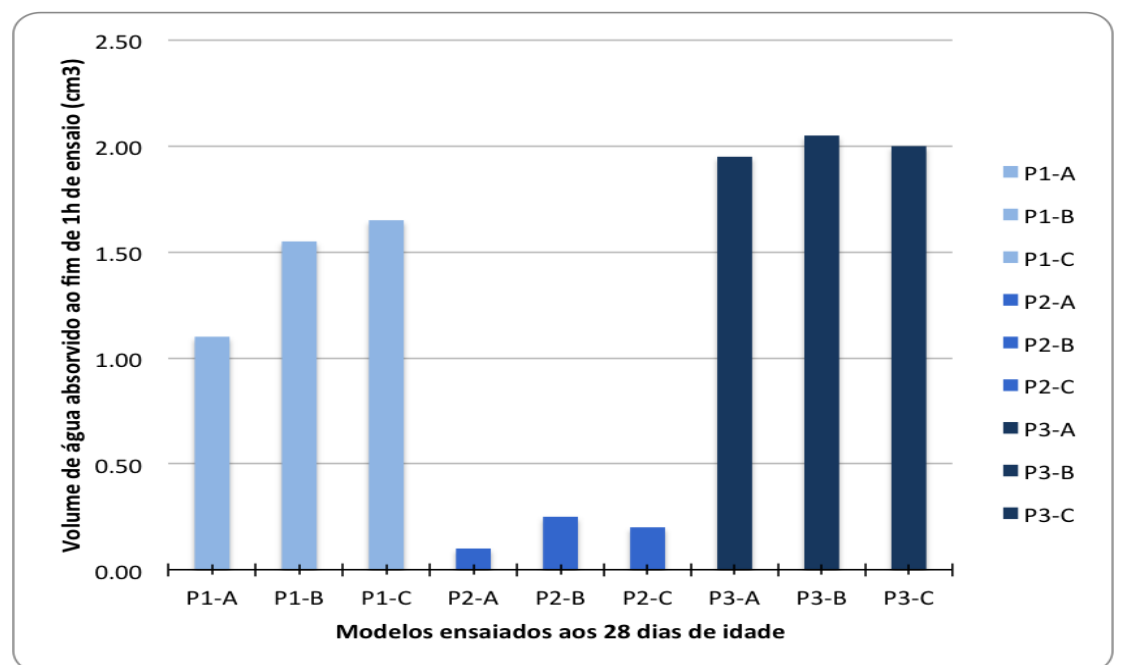

Figura 5. Influência do tipo de revestimento em argamassas de cal submetidas aos ensaios com o Tubo de Karsten 
Para uma melhor compreensão dos valores obtidos pelo Tubo de Karsten, é recomendada a análise de dois parâmetros: absorção de água aos 60 minutos $\left(\mathrm{m}^{3} / \mathrm{h}\right)$, já determinado nos resultados anteriores, e o coeficiente de absorção de água aos 60 minutos $\left(\mathrm{kg} / \mathrm{m}^{2} . \sqrt{\mathrm{h}}\right)$. Para o cálculo do coeficiente de absorção de água utilizou-se a expressão 1 :

$$
C_{\text {absorção }}=\frac{A_{b p} \times 10^{-3}}{A_{\text {contato }} \times 10^{-4} \times \sqrt{60}}
$$

Sendo:

- Cabsorção - coeficiente de absorção de água aos 60 minutos $\left(\mathrm{kg} / \mathrm{m}^{2} . \sqrt{\mathrm{h}}\right)$;

- Abp - massa de água absorvida aos 60 minutos (g);

- Acontato - área de contato do tubo com a superfície (considera-se igual a $\left.5.7 \mathrm{~cm}^{2}\right)$.

Os valores obtidos de absorção de água e do coeficiente de absorção para cada argamassa de cal são retratados na Tabela 1, possibilitando uma melhor distinção da permeabilidade das mesmas. As argamassas sem revestimento, visivelmente mais permeáveis que as demais, apresentam volume de água absorvida e coeficiente de absorção variando entre 1.10 e $1.65 \mathrm{~m}^{3} / \mathrm{h}$ e 0.25 e $0.38\left(\mathrm{~kg} / \mathrm{m}^{2} . \sqrt{\mathrm{h}}\right)$, respectivamente. As argamassas com revestimento de Tinta Acrílica apresentam os mesmos parâmetros, com valores variando entre 0.10 e $0.25 \mathrm{~m}^{3} / \mathrm{h}$ e 0.02 e $0.06\left(\mathrm{~kg} / \mathrm{m}^{2} . \sqrt{\mathrm{h}}\right)$, evidenciando a diferença que há entre a permeabilidade da mesma com a de uma argamassa sem revestimento.

Tabela 1. Resumo dos resultados com o tubo de Karsten aos 28 dias de idade

\begin{tabular}{|c|c|c|c|c|c|c|c|}
\hline \multirow{2}{*}{$\begin{array}{l}\text { Tipo de } \\
\text { revestimento }\end{array}$} & \multirow{2}{*}{ Designação } & \multicolumn{3}{|c|}{$\begin{array}{l}\text { Volume de água absorvida } \\
\qquad\left(\mathrm{m}^{3} / \mathrm{h}\right)\end{array}$} & \multicolumn{3}{|c|}{$\begin{array}{c}\text { Coeficiente de absorção } \\
\left(\mathrm{kg} / \mathrm{m}^{2} . \sqrt{ } \mathrm{h}\right)\end{array}$} \\
\hline & & Média & $\begin{array}{l}\text { Desvio } \\
\text { Padrão }\end{array}$ & CV (\%) & Média & $\begin{array}{l}\text { Desvio } \\
\text { Padrão }\end{array}$ & CV (\%) \\
\hline \multirow{3}{*}{ Tinta de Terra } & P1-A & 1.10 & 0.41 & 37.5 & 0.25 & 0.09 & 37.5 \\
\hline & P1-B & 1.55 & 0.57 & 37.0 & 0.36 & 0.13 & 37.0 \\
\hline & P1-C & 1.65 & 0.60 & 36.3 & 0.38 & 0.14 & 36.3 \\
\hline \multirow{3}{*}{ Tinta Acrílica } & P2-A & 0.10 & 0.03 & 33.3 & 0.02 & 0.01 & 33.3 \\
\hline & P2-B & 0.25 & 0.09 & 37.1 & 0.06 & 0.02 & 37.1 \\
\hline & P2-C & 0.20 & 0.06 & 31.7 & 0.05 & 0.01 & 31.7 \\
\hline \multirow{3}{*}{$\begin{array}{c}\text { Sem } \\
\text { revestimento }\end{array}$} & P3-A & 1.95 & 0.71 & 36.6 & 0.45 & 0.16 & 36.6 \\
\hline & P3-B & 2.05 & 0.78 & 38.0 & 0.47 & 0.18 & 38.0 \\
\hline & P3-C & 2.00 & 0.73 & 36.6 & 0.46 & 0.17 & 36.6 \\
\hline
\end{tabular}


Previsivelmente, os níveis de absorção da argamassa sem revestimento é superior à das demais argamassas, o que comprova 0 caráter impermeabilizante da pintura em uma superfície. A alta permeabilidade pode ser vantajosa na evaporação da umidade presente nas paredes, porém facilita a entrada de água por meio de chuvas, ocasionando no desgaste do material. No comparativo entre as pinturas, a tinta acrílica torna a argamassa muito pouco permeável, diminuindo significativamente os valores do volume de água absorvida e do coeficiente de absorção. Portanto, para o uso em restauro e manutenção de obras históricas, a tinta acrílica não é recomendada por não possibilitar a troca de umidade de forma significativa. CASTRO [6] afirma que a resina é a responsável pela impermeabilidade de uma tinta e que o maior teor de pigmento está relacionado à uma maior porosidade e opacidade. A tinta à base de solo tem em sua composição um baixo teor de resina (20\%) e alto teor de pigmentos, o que explica sua maior permeabilidade quando comparada à acrílica. Ainda que tenha maior permeabilidade, a tinta de solo ainda cumpre seu papel como tratamento superficial, embelezando e protegendo a argamassa; e para obras onde certa permeabilidade é desejável, esta tinta se apresenta como uma alternativa viável.

\section{CONCLUSÃo}

O trabalho realizado teve como intuito comparar a ação de duas diferentes pinturas na permeabilidade da argamassa de cal. A partir dos resultados obtidos pelos ensaios do tubo de Karsten, pode-se concluir que:

- A argamassa de cal, sem revestimento, apresenta alta permeabilidade, na ordem de $2,0 \mathrm{~m}^{3} / \mathrm{h}$

- A tinta à base de solo, reduz levemente a permeabilidade da argamassa de cal, permitindo a passagem de $1,40 \mathrm{~m}^{3} / \mathrm{h}$, em média.

- A tinta acrílica torna a superfície do substrato bastante impermeável, consequência do uso de resina acrílica como ligante.

- Para o uso em restauros e manutenções de obras históricas revestidas com argamassa de cal, a tinta acrílica não é recomendada, devido à sua impermeabilidade

\section{REFERÊNCIAS}

Santiago, C.C. Argamassas tradicionais de cal. Salvador. Edufba. 2007

Bianchin, A.C. Influência do proporcionamento dos materiais constituintes no desempenho de argamassas para reboco de recuperação em argamassas contaminadas por umidade e sais. Porto alegre. UFRGS. 1999

3 Cincotto, M.A. et al. Argamassas de revestimento: características, propriedades e métodos de ensaio. São Paulo. Instituto de pesquisas tecnológicas. 1995 Penas, F. E. Argamassas de cal hidráulica para revestimentos de paredes. lisboa. Universidade Técnica de Lisboa. 2008

Cardoso, F. P. Desenvolvimento de processos de produção e avaliação do 
desempenho de tintas para a construção civil manufaturadas com pigmentos de solos. Viçosa. UFV. 2015

6 Castro, C.D. Estudo da influência das propriedades de diferentes cargas minerais no poder de cobertura de um filme de tinta. Porto alegre. UFRGS. 2009

7 Faria, F. C. Produção de tintas naturais para construção civil: Testes de preparação, aplicação e avaliação do intemperismo acelerado. Curitiba. UFPR. 2008

8 Carvalho, A.F. Honório, L.M. Almeida, M.R. Santos, P.C. Quirino, P. E. Cores da terra: Fazendo tinta com terra. Viçosa. UFV. 2007

9 Selmo, S.M.S. Dosagem de argamassas de cimento Portland e cal para revestimento externo de fachadas dos edifícios. São Paulo. USP. 1989.

10 LNEC, revestimento de paredes. Ensaio de absorção de água sob baixa pressão. Lisboa. Laboratório nacional de engenharia civil. 2002

11 RILEM.13 mr Committee on mortars and renderings. Matériaux et constructions. 1980 